\title{
The Platform Construction of QQ Carrier for Ideological and Political Education in College
}

\author{
Hong-Bo XIU \\ College of Automobile \& Civil Engineering, Beihua University, Jilin 132013, China.
}

KEYWORD: QQ; Ideological and political education; Platform construction

ABSTRACT: With QQ instant messaging tool is widely used in contemporary college population, QQ group notifications is changing greatly influenced the thinking and behavior of contemporary college students. How to effectively be used of QQ to ideological and political education, is the ideological and political education worker's urgent task. In the paper, QQ platform was constructed as well as its realization of the module by analyzing the collection and dissemination of information. In the end, it expounds the results achieved in the development and it proposes improvement direction for QQ's further development.

\section{GENERAL INSTRUCTIONS}

Social surging wave of information technology, and the increasing popularity of network applications makes Internet access is no longer a new thing. Currently in China, the most popular instant messaging software is a network QQ. In this naive penguin Logo software, it has attracted hundreds of millions of Chinese Internet users. In 2000, the company greatly expanded Tencent QQ functions, in addition to the original communication, also created games, shopping, music, blog, news service platform, service face quickly widened. According to Tencent official statistics, the first quarter of 2010, QQ number of active accounts reached 568.6 million, QQ peak simultaneous online user accounts reached 105.3 million, "QQ space" active accounts reached 428 million, "QQ game" portal PCU number (including mini casual games only) was 6.8 million. QQ increasingly become a staple of conversation, more and more people use QQ exchange. Especially mobile IM development and use, not only to meet the users to communicate with friends anytime, anywhere, with text messaging and mobile social networking, pictures, voice and video, and interactive elements such as geographic location, two-dimensional code scanning capabilities make communication even more easy and fun, so use QQ mobile phone users has grown, users pay gradual increase, "online" has become a common state.

According to "the 33rd China Internet Development Statistics Report Network" in January 2014 China Internet Network Information Center (CNNIC) released, as of December 2013, China's instant messaging users scale up to 532 million, an increase compared to the end of 201264.4 million, an annual growth rate of $13.8 \%$. Instant messaging usage rate of $86.2 \%$, compared with the end of 2012 increased by 3.3 percentage points, the utilization rate in the first place to chat as the main function of QQ Chinese Internet users continues to lead the first major applications.



Figure 1. QQ group display page 
QQ should influence the thinking and behavior of college students, counselors, changing the ideological and political education work. Faced with this idea and cultural exchanges have become increasingly prominent position in the important network of interpersonal communication, ideological and political education can not be indifferent, it must be integrated into their vision, and actively carry out the lively ideological and political education. Therefore, the study QQ media on ideological and political education and its countermeasures has important theoretical and practical significance.

QQ on the opportunities and challenges to the ideological and political education and QQ brought and applied research in the ideological and political education has important theoretical value. On the one hand, the subject from the perspective of a network carrier, to expand the space of ideological and political theory education students, as well as the carrier will affect QQ ideological and political education to support research to provide a new perspective, enriched Carriers ideological and political education, deepen the network Ideological and political Education. On the other hand, as a network of social media, QQ can put computer science, communication, education, management and other disciplines theory together, become interdisciplinary research complex. Study QQ on Ideological and Political Education and Countermeasures focusing learn knowledge utilization of network communication, not only promoted the development of ideological and political education, but also for deepening other subjects, especially theoretical depth and practice of ideological and political education communication also has a major theoretical significance.

\section{QQ INFLUENCE ON THE IDEOLOGICAL AND POLITICAL EDUCATION}

Meanwhile, the real need is the driving force to promote the development of ideological and political education of college students. QQ study on the impact of ideological and political education and applied research strategy is a subject which has great practical significance.

First, the innovation of ideological and political education carrier, enhance the effectiveness of College Students' Ideological and Political Education. In QQ as the carrier of ideological and political education, you can extend its reach and influence, so that students get a wide range of social information in the QQ information dissemination, but also to accept the ideological and political aspects of information, influenced by ideological and political education, so as to continuously improve their own ideological and moral qualities. Not only that, add friends through QQ group and can also affect other large populations, thus expanding the influence of ideological and political education. And multimedia qualities QQ carrier spread ideological and political education content becomes interesting, help to strengthen the ideological and political education information dissemination force, so as to enhance the appeal and attractiveness of the ideological and political education.

Second, help overcome difficulties traditional ideological and political education model to promote ideological and political education modernization. Traditional ideological and political education, means a single, monotonous method, the strength of the weak and inefficient. QQ become the new carrier of ideological and political education of college students can fully mobilize the initiative and enthusiasm, instant communication closer to the actual thinking of students, promote ideological and political education more relevant and effective in the past to overcome the ideological and political education is not strong drawbacks. Modern ideological and political education includes a wide range of content, which is the modern means an important aspect, namely communication carriers continue to use modern science and technology arm, the transformation of education information, in order to achieve optimal means of education. With QQ network platform, a network of information and communication technologies, in order to adapt to and use of healthoriented QQ, QQ full play to the positive impact on the ideological and political education, and promote the modernization of ideological and political education of college students the means to accelerate the pace of $\mathrm{m}$

Third, help solve the practical problems of information society brings to the network moral construction. QQ network is double-edged sword, it not only provides a new channel for the carrier and the ideological and political education, ideological and political education but also pose a 
serious challenge to the current network will be placed in front of moral ideological and political educators question. Positive impact on the ideological and political education and the negative impact of systematic research QQ, QQ explore this measure from the face of the media should take the ideological and political education, and effectively improve the subject of education ideological and political education communication skills and media literacy education objects effectively college students to solve practical problems of thinking and living.

\section{QQ POSITIVE IMPACT ON THE IDEOLOGICAL AND POLITICAL EDUCATION}

QQ new media features and rich functionality determine QQ has become a daily work, study, live and play an important platform, but college students are the main force QQ use the Internet on college students' learning, social interaction, resolve pressure and other aspects have had a positive impact. Needless to say, college students widely use the unique advantages of QQ and QQ network communication, gave contemporary strengthen and improve ideological and political education has brought new opportunities.

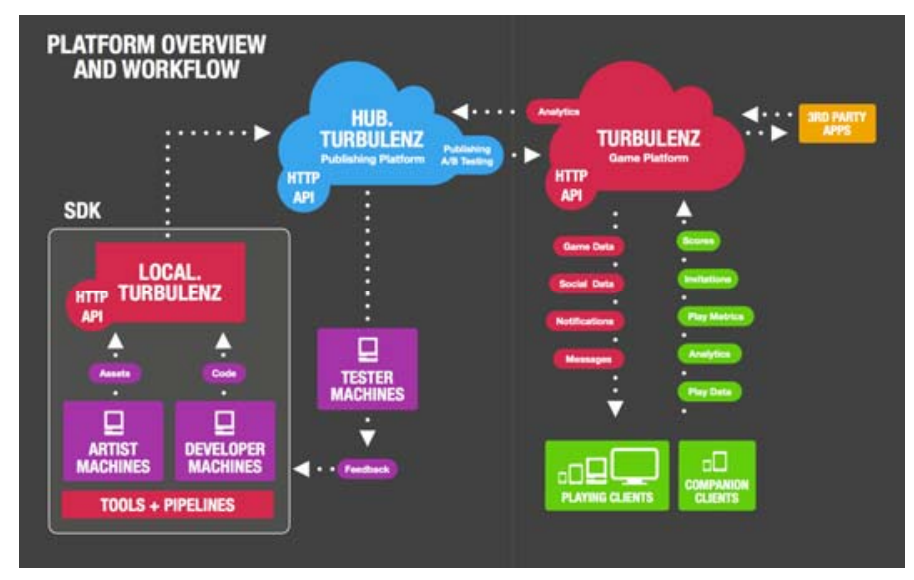

Figure 2. QQ chat authorization hierarchy diagram

Since the spread QQ instant messaging audiences certainty, continuity, real-time communication, flexibility and other means of communication, it also has a built-propagation network infrastructure more stable, has a higher efficiency in the dissemination of information. Therefore, the use QQ spread of ideological and political education in favor of ideological and political education rich selection of content and use, to enhance the effect of ideological and political education. Chat is a point or points on the Internet across the network communication protocol generated based communication. It provides instant file, text, images, voice, video and other media data in multiple formats, making it easy for people to communicate. As a widely used instant messaging software, QQ media has the features and functionality of multimedia teaching can be a modern teaching tool.

Relying on QQ and service platform for college students ideological and political education, ideological and political education can use multimedia nature of information dissemination QQ produced a rich creative ideological and political education, freedom to choose and use different resources of ideological and political education, ideological and political education information through text, animation, pictures, emoticons, web links, voice, video, instant document and file sharing and other forms of flexible, vividly presented in front of students, so that the content of ideological and political education becomes interesting and intuitive, selectively strengthen the ideological and political education expressive and reproduce the force, thereby greatly enhancing the appeal and attractiveness of the ideological and political education to mobilize university students access to information initiative and participation. For example, the use of multimedia means of communication qualities can instantly send some contrasting comic, humorous language, education, micro-video. When college students with online communication, you can also use voice calls, video conversations, making learning more interesting, naturalization, humane, improve the effectiveness of education. Multimedia means of communication for the network QQ spread 
ideological and political education content increased influence extend the coverage of the spread of ideological and political education.

QQ network performance information visible in the diverse, realistic interactive elements, illustrations, sensual superb, strongly attracted the contemporary college students to use. This will break the solemn atmosphere of the traditional ideological and political education, creating a lively and colorful image of the educational environment, to make up for the limitations of traditional media in disseminating information vivid, memory retrieval, format switching and other aspects of the operation description help to improve the quality and efficiency of ideological and political education to interact.

Cultivating people is a fundamental task of ideological and political education, not only to use appropriate educational methods and educational content should be with the times. QQ instant communication exchanges not only provide a powerful ideological and political education of teaching tools and methods, but also for ideological and political education evaluation provides a new way to help improve the ideological and political education of relevance to teaching new life and vitality.

Implementation of ideological and political education is inseparable from educators and educational interactive objects behavior, is an information transfer, receive and process feedback educational activities. Ideological and political education in the past were often taken to be one-way indoctrination methods, college students ignore individual needs and capabilities, suppression of initiative and creativity of college students. QQ online communication has become a dynamic ideological camp students, ideological and political education effectively help grasp the ideological and political situation of contemporary college students, but also for the evaluation of ideological and political education to open a more advanced network feedback mode. Traditional media such as newspapers, radio and television in general is the way to take a one-way communication, that is, information is mainly produced by unilateral communicators and provided the audience can only passively receive its feedback tend to be lagging behind. The media have taken QQ instant interactive communication, whether it is the content of classroom teaching evaluation network feedback or teachers are conducive to improving ideological and political education targeted.

\section{QQ NEGATIVE IMPACT ON THE IDEOLOGICAL AND POLITICAL EDUCATION}

QQ has changed the way of thinking of contemporary college students, communication, presentation and interpersonal manner, with its abundant resources, real-time information, open platform, the virtual space, interactive equality, state secret and other characteristics of a university student self-expression vital space. This expansion is both ideological and political education of college students a new way, but also to spread all kinds of harmful information provides an opportunity for ideological and political education of the normative, the object of education, educational status and educational environment can not be brought avoid negative effects.

Use QQ contemporary college students is an important way of social networking, the entertainment media increasingly become a platform for the exchange of teachers and students. But the pan-entertainment atmosphere of ideological and political education authority will weaken the power of discourse, ideological and political education easily lead to a lack of seriousness. Compared with traditional media, QQ spread open, interactive, information capacity and regeneration of significant features, and everyone has a say, spontaneous trail information can be seen everywhere, the dominant position of ideological and political education of educators threatened, the body of the pan will spread deconstruction of ideological and political education in an orderly guide to some extent.

College Students' preference for a variety of network languages, QQ exchanges good buckwheat missing language network and in-depth entertainment spirit and greatly reduce the role of authoritative discourse of ideological and political education, weakening the seriousness of the spread of ideological and political education. Students chat on QQ negative impact of the degree of recognition, the highest "QQ chat easily lead to pan-entertainment" (56.60\%), followed by "QQ chat easily lead to real interpersonal trust crisis" (17.10\%) and, finally, "QQ chat easily lead to irrational emotions" (14.50\%). Visible forms of entertainment QQ chat easily lead to the spread of pan-entertainment atmosphere, college students speak freely in QQ exchange, mutual entertainment, feel free to use a variety of language and culture. 


\section{CONCLUSIONS}

Changing social media QQ bring people not only in life and entertainment, strong, progressive network technology QQ's development provides a strong support to our study brings a new way. Currently, the carrier carried out by means of QQ ideological and political education, ideological and political education of contemporary college students need to work to enhance media literacy, active Students' QQ group opinion leaders, consciously shaping QQ audience to support the initiative occupation the network ideological and political education of new positions.

Social media development of mobile Internet era has greatly changed the audience to accept, production and dissemination of information on ways and means. According to McLuhan's theory point of view, QQ creating a new situation of interpersonal communication and mass communication combining these forms of communication emphasized the status and role of communicators, individuals directly influence others through the production and dissemination of information in the virtual world in expanding their social influence. This situation demands the audience accomplishment is even more prominent. The majority of QQ users, it should be like a bird feather fondness love their QQ account number and reputation. In a rapid transformation of social development, QQ new media can function properly is a blessing of the whole society, so that will help improve a tool that should not be rumors and recreation injury was black and blue.

\section{REFERENCES}

Lu Zhiguo, Yin Xue, Jiang Lili social networking information sharing space environment. Digital Library Forum, 2009 (2).

ZHENG Zhi hair, Liujuan Juan .QQ: New Carrier of Ideological and Political Education Advantages and Disadvantages of Guangxi College of Education, 2010 (4).

Yao Jinyun, Pan Luyi .QQ spread of ideological and political education Challenge and Countermeasures. Education and Professional, 2011 (2).

Liu Chunhua .QQ visit: exchanges of teachers and students gossiping in the spirit of Hubei Normal University (Philosophy and Social Sciences), 2010 (5).

Interpersonal communication and interpersonal harmony Yellow Chenxian Gang. QQ Context of Kunming University of Technology (Social Science Edition), 2009 (4).

HONG Xia Yang .QQ Group - College Students' Party's powerful platform for contemporary educational theory and practice, 2010 (3).

Gui bamboo effect. QQ group in the class collective cultural construction of Hebei Normal University for Nationalities, 2012 (4).

Bin .QQ applied research group in college counselors work counselors, 2011 (2).

Li Xiang .QQ group in the application of the Ideological and Political Theory Teaching, Nanchang College of Education, 2012 (3).

Tang Wenyi .QQ group application inquiry in teaching. Ningde Teachers College (Natural Science), 2011 (3).

Yao Jinyun .QQ revelation interpersonal communication in the University Ideological and Political Education. School Party and ideological education, 2011 (8). 